\title{
VARIASI ZONA LEMAH STRUKTUR INTERNAL GUNUNG LOKON BERDASARKAN STUDI SEISMO-VULKANIK
}

\author{
Silvester Anthe ${ }^{1)}$, Guntur Pasau ${ }^{1)}$, Adey Tanauma ${ }^{1)}$ \\ ${ }^{1)}$ Program Studi Fisika, FMIPA, UNSRAT \\ e-mail: silvesteranthe@gmail.com,pasaujunior@gmail.com, adeytanauma@yahoo.com
}

\begin{abstract}
ABSTRAK
Indonesia merupakan negara gunungapi dengan jumlah gunungapi aktif terbanyak di dunia yaitu 129 buah yang tersebar di jalur Cincin Api (Ring of fire) Pasifik dan sekitar 8\% berada di Propinsi Sulawesi Utara. Gunung Lokon merupakan salah satu dari 129 buah gunungapi aktif di Indonesia yang sering erupsi dan mengalami perubahan Zona lemah sejak tahu 1829. Dalam penelitian ini dilakukan untuk posisi kantung magma gunung Lokon dan variasi zona lemah struktur internal gunung Lokon. Penelitian ini menggunakan data sekunder dari PVMBG pos PGA LokonMahawu Kakaskasen, Tomohon. Hasil dan analisis tersebut dipakai sebagai sumber mitigasi bencana dan perkembangan ilmu pengetahuan kegunungapian.
\end{abstract}

Kata Kunci : zona lemah gunung Lokon, Gunung Lokon,

\section{WEAK ZONE VARIATION INTERNAL STRUCTURE MOUNT LOKON BASED ON SEISMO-VULCANIC STUDY}

\begin{abstract}
Indonesia is a volcanic country with the highest number of active volcanoes in the world that is 129 pieces scattered in the path of the Ring of Fire (Ring of Fire) Pacific and about 8\% is in the province of North Sulawesi. Mount Lokon is one of 129 pieces of active volcanoes in Indonesia are often erupted and weak zone changes since out 1829. In this research, to position of Lokon mountain magma chamber and internal structure variations weak zone Lokon mountain. This study uses secondary data from PVMBG post PGA Lokon -Mahawu Kakaskasen, Tomohon. Results and analysis are used as a source of disaster mitigation and development of science volcanology.
\end{abstract}

Keywords: Mount Lokon weak zone, Mount Lokon.

\section{PENDAHULUAN}

Indonesia merupakan negara gunungapi dengan jumlah gunungapi aktif terbanyak di dunia yaitu 129 buah yang tersebar di jalur Cincin Api (Ring of fire) Pasifik dan sekitar $8 \%$ berada di Propinsi Sulawesi Utara (Gambar 1). Banyaknya gunungapi memberikan potensi besar berupa energi panas bumi dan keanekaragaman geologi (geodiversity), namun aktivitas erupsinya berpotensi menimbulkan bencana. Erupsi gunungapi dapat menimbulkan korban jiwa, gangguan kesehatan, kerusakan infrastruktur, berdampak pada cuaca dan menimbulkan persoalan-persoalan sosial. Banyaknya gunungapi di negara kita juga belum diimbangi dengan jumlah periset dan kegiatan riset gunungapi. Padahal, aktivitas vulkanik gunungapi berdampak luas pada berbagai aspek kehidupan masyarakat. Riset terhadap perilaku erupsi gunungapi di Indonesia dan Sulawesi Utara sangat penting dilakukan untuk memonitoring dan prediksi aktivitas vulkanik, mitigasi dan penanggulangan bencana.

Gunung Lokon merupakan salah satu dari 129 buah gunungapi aktif di Indonesia yang sering erupsi (Badan Geologi, 2011). Pada tahun 2013 ini, aktivitas erupsinya masih berlangsung. Karakteristik erupsinya adalah erupsi eksplosif bertipe Vulkanian dan manifestasi eksplosifnya berupa aliran awan panas, lontaran bom vulkanik (material pijar), 


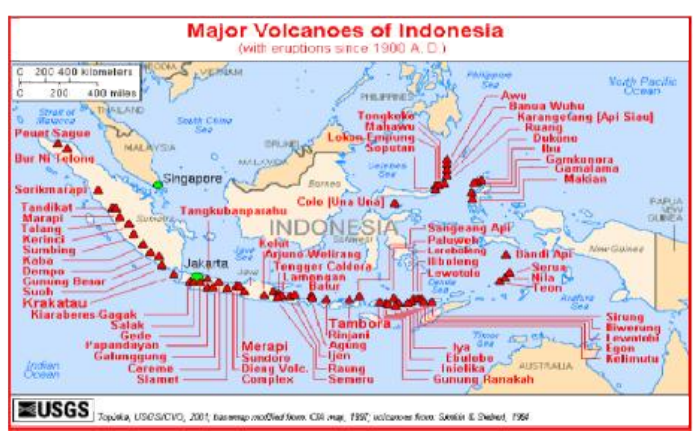

Gambar 1 Sebaran gunungapi di Indonesia

jatuhan pumis, lapili, dan abu serta hembusan gas beracun (Badan Geologi, 2011; Suparman dkk, 2010). Berdasarakan sejarah erupsinya gunung Lokon mengalami perubahan zona lemah titik erupsi yang semulanya berada pada puncak gunung Empung dan kemudian pada tahun 1829 erupsi terjadi pada kawah Tompaluan berdasarkan hal inilah perlu adanya riset mengenai variasi zona lemah struktur internal gunung Lokon.

\section{METODE PENELITIAN \\ Waktu dan Tempat Penelitian}

Penelitian dilakukan di Pusat Vulkanologi dan Mitigasi Bencana Geologi pos Pengamatan GunungApi Lokon dari bulan Oktober - Desember 2014

Alat dan bahan yang digunakan dalam penelitian ini adalah :

Alat

1. Komputer

2. Software SEISAN

3. Software ORIGIN

4. Software SWARM

5. Software GAD

Bahan

1. Data seismik gunung Lokon periode $2011-2014$

2. Data hiposenter dan erupsi gunung Lokon

\section{Prosedur Kerja}

Langkah kerja yang dilakukan dalam penelitian ini adalah :

1. Menghimpun data gempa vulkanik gunung api Lokon periode 2011-2014

2. Mengelompokkan data gempa yakni gempa vulkanik dalam dan vulkanik dangkal, kemudian dilakukan picking untuk penentuan waktu tiba gelombang $\mathrm{P}$ dan gelombang $\mathrm{S}$
3. Data waktu tiba gelombang $\mathrm{P}$ dan $\mathrm{S}$ digunakan utuk menentukan titik perpotongan antar stasiun

4. Data perpotongan antar stasiun kemudian digunakan untuk menentukan posisi hiposenter

5. Menganalisis data sebaran hiposenter

\section{HASIL DAN PEMBAHASAN Data dan Pemilihan Data}

Data yang digunakan dalam penelitian ini adalah data aktivitas seismik gunung Lokon periode Desember 2013- Juli 2014 yana dipantau secara menerus dengan peralatan analog maupun digital di Pos Pengamatan Gunungapi (PGA) Gunung Lokon - Gunung Mahawu di Kakaskasen, Tomohon. Pemantauan kegempaan Gunung Lokon menggunakan 5 stasiun seismik yang terdiri dari stasiun Empung (EMP), Sea (SEA), Kinilow (KIN), Tatawiran (TTW) dan Wailan (WLN). Namun pada periode tahun 2014, pemantaun kegempaan hanya menggunakan stasiun seismic EMP, KIN dan WLN, karena stasiun seismik lainya tidak beroperasi dengan baik akibat terlanda material letusan. Data gempa analog ditransmisikan dengan gelombang radio dari setiap stasiun seismik di lapangan menuju Pos PGA Lokon. Data diakuisisi dan menjadi data digital dengan sistem earthworm dan argalite serta disimpan dalam format seisan dan win.

Dari data seismik vulkanik gunug Lokon kemudian dikelompokkan untuk gelombang vulkani A (vulkanik dalam) dan vulkanik B (vulkanik dangkal) (lihat Gambar 2) sehingga data yang dikumpul dilakukan proses picking atau penentuan waktu tiba gelombang P dan gelombang S. Seperti pada gambar 3.

(a)

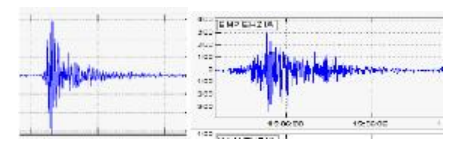

(b)

Gambar 2 (a) Jenis gelombang vulkanik A atau vulkanik dalam (b) Jenis gelombang vulkanik B atau vulkanik dangkal 


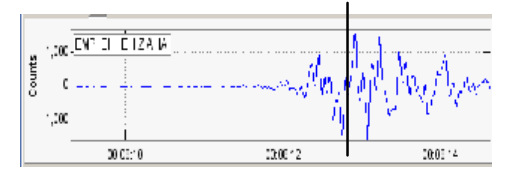

Gambar 3 Proses picking atau penentuan waktu tiba gelombang $\mathrm{P}$ dan $\mathrm{S}$. Garis warna merah menunjukkan waktu tiba gelombang $\mathrm{P}$ dan garis merah menunjukkan waktu tiba gelombang S.

Data gelombang yang kemudian di tentukan waktu tiba gelombang $\mathrm{P}$ dengan cara, apabila suatu gelombang naik pada awal sinyal gelombang terekam kemudian diplot sebagai gelombang $\mathrm{P}$ lalu ditentukan waktunya dengan melihat waktu yang tercatat, kemudian apabila gelombang turun dan naik kembali pada daerah itulah diindikasikan sebagai gelombang $\mathrm{S}$ tiba, yang kemudian di beri tanda untuk melihat waktu tibanya. Untuk mendapatkan waktu beda antara waktu tiba gelombang $\mathrm{P}$ dan $\mathrm{S}$ yakni waktu tiba gelombang $\mathrm{P}$ dan $\mathrm{S}$ dikurangi, setelah itu dicatat lama gelombang, kemudian semua data waktu tiba gelombang dan lama gelombang dicatat untuk penentuan hiposenter.

\section{Penentuan Hiposenter}

Data gempa yang telah di picking kemudian dicari titik perpotongan antar stasiun penerima sinyal lalu diplot sehingga diperoleh data sebaran hiposenter gunung Lokon periode Desember 2013- Juli 2014 yang menjadi acuan penelitian untuk kemudian dianalisis untuk menentukan posisi kantung magma dan variasi zona lemah struktur internal gunung Lokon. Seperti yang terlihat pada gambar 2. Oleh karena berdasarkan data inilah kajian vulkanisme gunung Lokon dapat diketahui.
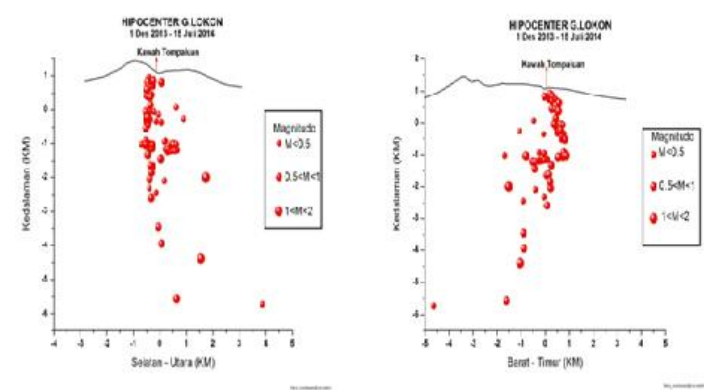

Gambar 4 Sebaran hiposenter Tahun 2014.

Dari data aktivitas seismik gunung
Lokon tahun 2014 didapat sebaran episenter gempa vulkanik, dimana episenter gempa vulkanik adalah pusat gempa yang diakibatkan oleh aktivitas vulkanik kemudian ditarik tegak lurus ke permukaan bumi. Sebaran episenter gunung Lokon tahun 2014 menggambarkan pola migrasi magma pada daerah gunung/kawah yang cenderung terkonsentrasi pada daerah baratlaut gunung Lokon, yang kemudian dapat diartikan sebagai daerah variasi zona lemah struktur internal gunung Lokon yang berarah baratlaut dan daerah seismik vulkanik gunung Lokon, seperti terlihat pada gambar 5 .

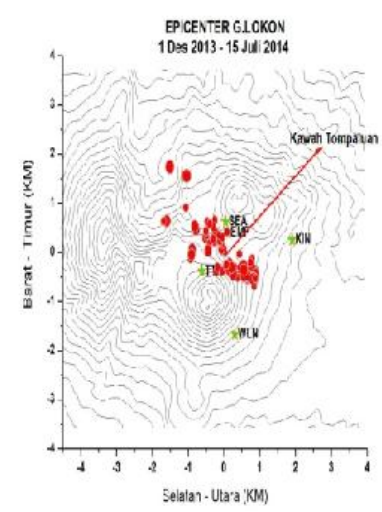

Gambar 5 Sebaran episenter gunung Lokon Tahun 2014

\section{PEMBAHASAN}

\section{Penentuan Posisi Kantung Magma}

Dalam penentuan posisi kantung magma berdasarkan sebaran hiposenter (gambar 3), dimana kantung magma adalah daerah yang sedikit aktivitas seismik hal ini bisa terlihat bahwa akumulasi gempa vulkanik cenderung membnetuk pola kantung dan terkonsentrasi pada kedalaman $2000 \mathrm{~m}$ dibawah kawah Tompaluan dan kemudian gempa-gempa tersebut terlihat pada kedalaman kurang lebih $3000 \mathrm{~m}$ pada daerah ini diduga kuat sebagai posisi kantung magma (gambar 6)

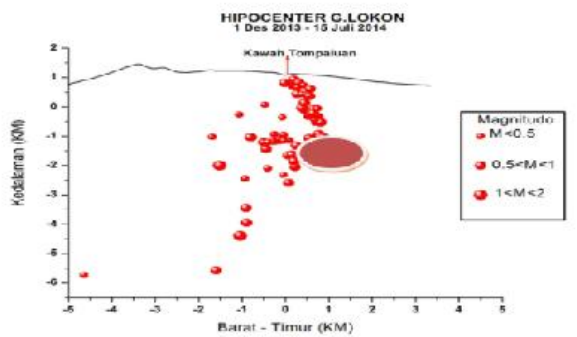

Gambar 6 Posisi kantung magma gunung Lokon berdasrkan sebaran hiposenter 
Dari gambar diatas dapat di artikan bahwa daerah yang diduga kuarng sebagai daerah kantung magma merupakan daerah asesimik atau daerah dimana sedikit aktivitas seismic hal ini dikarenakan gempa yang diakibatkan oleh magma hanya terjadi pada daerah dinding magma yang terjadi kontak langsung antara magma dengan batuan, pada daerah timur sulit ditentukan batasan kantung hal ini diakibat oleh batuan yang berada di sebelah timur kawah Tompaluan sangat keras sehingga tidak dapat diterobos oleh magma.

\section{Pola Variasi Zona Lemah Struktur Internal Gunung Lokon}

Dalam menentukan variasi struktur internal gunung Lokon melalui aktivitas seimo-vulkanik, data untuk satu tahun tidaklah akurat, maka dihimpun data hiposenter tahun 2011 samapai 2013. Data diambil pada saat peningkatan aktivitas gunung lagi meningkat sehingga hasil lebih akurat dan terlihat jelas dalam analisa variasi zona lemah struktur internal gunung Lokon, pada periode tahun 2011-2013 gunung Lokon mengalami erupsi jangka pendek, gunung Lokon mengalami erupsi jangka pendek ini diakibatkan variasi zona lemah yang mengakibatkan magma cenderung terdorong keatas oleh karena daerah suplai magma awal telah berubah menjadi batuan yang keras sehingga magma mencari zona lemah yang baru, hal ini terlihat dari data sebaran hiposenter periode tahun 2011 sampai 2014.

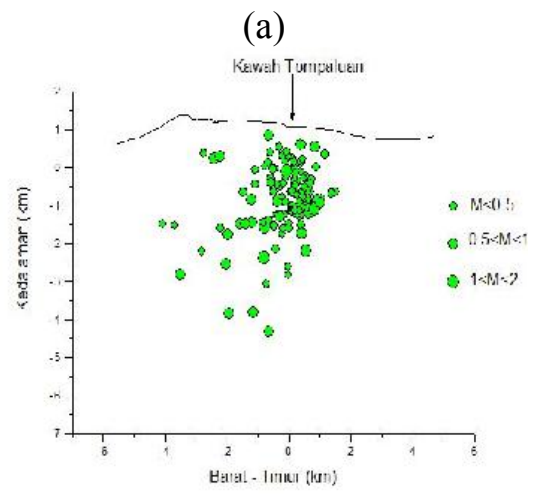

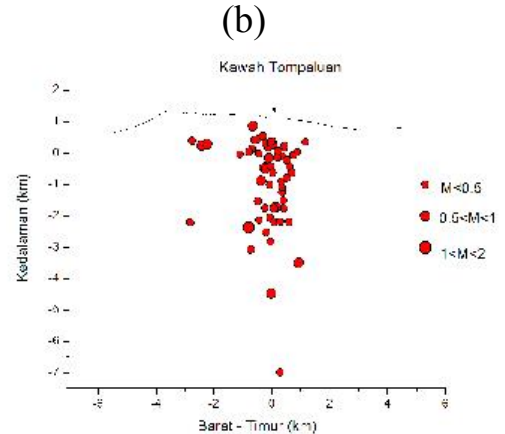

(c)

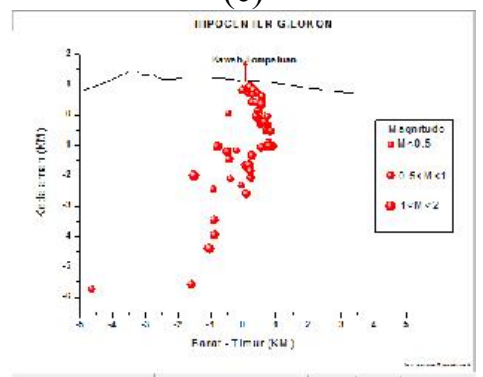

(d)

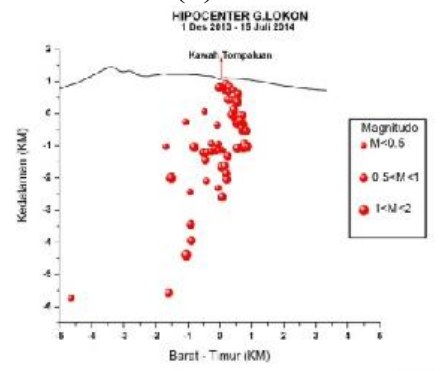

Gambar 7 (a) sebaran hiposenter gunung Lokon tahun 2011, (b) sebaran hiposenter gunung Lokon tahun 2012, (c) sebaran hiposenter gunung Lokon tahun 2013

Sebagaimana diketahui bahwa kompleks Lokon-Empung Pada abad ke-14 pusat letusan Kompleks Gunung Lokon Empung berada di puncak Gunung Empung Sejak 1829 titik letusan bergeser ke arah selatan, yaitu di pelana antara puncak Gunung Lokon dan puncak Gunung Empung yang dikenal dengan Kawah Tom-paluan. Interval letusan yang pendek antara $1-8$ tahun, sedangkan interval letusan yang panjang sekitar 64 tahun yakni antara tahun 1829 sampai tahun 1893.(kristianto.,dkk 2011)

Dari hal inilah maka variasi zona lemah struktur internal gunung Lokon dapat dilihat dari tahun 2011 sampai tahun 2014 sangat terlihat dimana aktivitas seismic gunung Lokon cenderung terkonsentrasi kearah baratlaut kawah Tompaluan dan dari 
pola sebaran hiposenter gunung lokon tahun 2014 (lihat gambar 3) terlihat bahwa pola variasi zona lemah cenderung kearah barat laut kawah Tompaluan.

Hal ini diakibatkan oleh pergerakan lempeng Sangihe yang relative timur -barat hal ini dapat diartikan bahwa aktivitas gunung Lokon tidak hanya diakibatkan oleh aktivitas vulkanik murni tetapi diakibat pula oleh aktivitas tektonik. sebagaimana Lecuyer dkk dalam ., (1995 dan 1997) telah melakukan penelitian mengenai tektonik di sekitar Kaldera Tondano, termasuk di dalamnya Kompleks Lokon - Empung. Dari hasil interpretasi struktur geologi yang berkembang, khususnya di sekitar Lokon Empung menunjukkan bahwa terdapat beberapa struktur sesar (Gambar 8). Dengan demikian diduga bahwa deformasi yang terjadi tidak saja karena aktivitas vulkanik, tetapi juga dipengaruhi oleh aktivitas tektonik

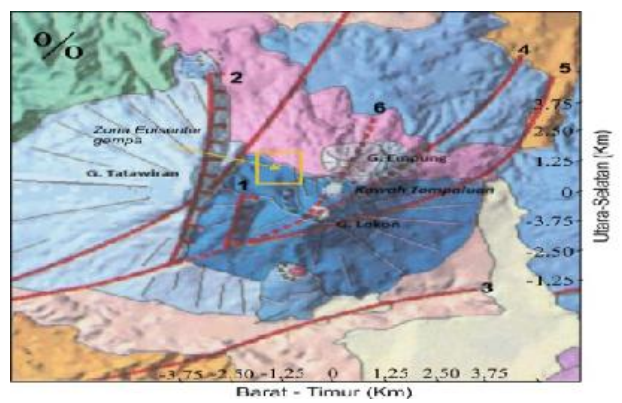

Gambar 8 Struktur geologi di Kawah Tompaluan dan sekitarnya (modifikasi dari Lecuyer dkk., 1995).

Dari gambar 8 ditafsirkan bahwa gempa-gempa vulkanik yang terekam berasosiasi dengan aktivitas sesar normal nomor 1 dan sesar yang memotong Kawah Tompaluan, nomor 6 . Arah pergeseran vektor di bagian lereng dipengaruhi oleh pergerakan sesar nomor 4 dan nomor 5 , sedangkan di daerah distal, pergeseran vektor yang berlawanan arah (Gambar 8) kemungkinan besar diakibatkan oleh pergerakan sesar mendatar, nomor 3 di sekitar Danau Tondano.

\section{KESIMPULAN}

1. Posisi kantung magma gunung Lokon diduga kuat berada pada kedalam 2000-3000 meter dari kawah Tompaluan yang terlihat dari sebaran hiposenter gunung Lokon tahun 2014.

2. Variasi struktur internal gunung Lokon pada daerah barat kawah Tompaluan zonanya lebih lemah yang diakibatkan oleh aktivitas vulkanik dan tektonik atau dapat dikatakan bahwa variasi zona lemah gunung Lokon berada pada daerah barat kawah Tompaluan.

\section{DAFTAR PUSTAKA}

Andri, 2006, Pemodelan Kedepan Struktur Kecepatan di Bawah Kompleks Krakatau dengan Menggunakan Solusi Persamaan Gelombang dan Persamaan Eikonal, Teknik Geofisika, ITB

Diklat Pelaksana Pemula Pengamat Gunungapi Baru. 2010. Pengenalan seismologi gunungapi. Pusat Vulkanologi dan Mitigasi Bencana Geologi

Gunawan, H., Triatuti, H., Rosadi, U., Omang, A.,2009, Studi Geofisika Gunung Lokon Pengolahan Data Deformasi dan Seismik, Laporan Penelitian, Pusat Vulkanologi dan Mitigasi Ben-cana Geologi, Badan Geologi.

Hendrajaya,L. 2011. Fisika Gunungapi. Makalah disampaikan pada acara Kolokium PVMBG 3 Maret 2011. Bandung

Kristianto, Haerani, N., Basuki, A., Mulyana, I., dan Manthovanie, A., 2011a, Laporan TanggapDarurat Letusan G. Lokon Sulawesi Utara, Pusat Vulkanologi dan Mitigasi Bencana Geologi

Kristianto, Gunawan, H., Haerani, N., dan Primu-lyana, S., 2012, Laporan dan Kajian Vulkanisme, Pusat Vulkanologi dan Mitigasi Bencana Geologi, Bandung.

Kusumadinata, K., 1979, Data Dasar Gunung Api Indonesia, Direktorat Vulkanologi.

Lecuyer, F., Gourgoud, A., dan Vincent, P., 1995, Volcanic Hazards Related to Tondano Caldera, North Sulawesi Indonesia, Per. Mineral, 64, 201 203.

Lee, W.H.K dan Stewart, S.W. 1981. Principle and Application of Microearthquake Network. USGS. California

Mulyadi, D., Hendrasto, dan M., Suradji, I. , 
1990,Laporan Pemetaan Geologi Gunung Lokon - Empung, Sulawesi Utara, Direktorat Vulkanologi, Bandung

Nishi, K., 2001, A three-dimensional robust seismic ray tracer for volcanic regions, Earth Planets Space, 53, 101-109.

Sabry M., Mekanisme Letusan G. Kelud 10 Februari 1990 Berdasarkan Analisa seismik, GM-ITB, 1993

Siswowijoyo, S., Seismologi Gunungapi, Analisa Gempa dan Hubungannya dengan Tingkat Kegiatan Gunungapi, Direktorat Vulkanologi, 1981

Suparman, Y .,Kristianto, Gunawan, H., Solihin, A., Basuki, A., dan., 2011b, Seismisitas

Gunungapi Lokon, Pusat Vulkanologi dan Mitigasi Bencana Geologi.

Suparman, Y ., Saing., B., U., dan Zaenudin., A., Erupsi gunung Lokon berdasarkan kegempaan deformasi dan geokimia, Pusat Vulkanologi dan Mitigasi Bencana Geologi, 2013.

Wittiri, S.R., Pardyanto, L., Pengertian Istilah Seismik Gunungapi, Direktorat Vulkanologi. 